\title{
Metabolic Rate in Different Rat Brain Areas During Seizures Induced by a Specific Delta Opiate Receptor Agonist
}

\author{
JUDITH HAFFMANS, RON DE KLOET* and MIHAILO R. DZOLJIC \\ Department of Pharmacology, Medical Faculty, Erasmus University Rotterdam, P.O. Box 1738, 3000 DR Rotterdam and \\ ${ }^{*}$ Rudolf Magnus Institute, Medical Faculty, State University, Vondellaan 6, \\ 3521 GD Utrecht (The Netherlands)
}

(Accepted October 18th, 1983)

Key words: 2-deoxyglucose - delta opiate agonist — epilepsy - amygdala — hippocampus — subiculum

\begin{abstract}
The glucose utilization during specific $\delta$ opiate agonist-induced epileptiform phenomena, determined by the [ $\left.{ }^{14} \mathrm{C}\right] 2$-deoxyglucose technique (2-DG), was examined in various rat brain areas at different time intervals. The peak in EEG spiking response and the most intensive 2-DG uptake occurred $5 \mathrm{~min}$ after intraventricular (i.v.t.) administration of the $\delta$ opiate receptor agonist. The most pronounced 2-DG uptake at this time interval can be observed in the subiculum, including the CA1 hippocampal area, frontal cortex and central amygdala. A general decrease of glucose consumption, compared to control values, is observed after $10 \mathrm{~min}$, in all regions, with exception of the subiculum.

Since functional activity and 2-DG uptake are correlated, we suggest that the subiculum and/or CA1 area, are probably the brain regions most involved in the enkephalin-induced epileptic phenomena.
\end{abstract}

\section{INTRODUCTION}

There is evidence that endorphins may play a role in epileptogenesis ${ }^{2,18}$. The target area of this action seems to be the limbic system ${ }^{9,10}$, and specifically the hippocampus ${ }^{3,7}$. The increase of neuronal excitation caused by opiates in the hippocampal area is of particular interest, since opiates were found to depress neurones in other brain regions ${ }^{10}$. Because functional activity and energy metabolism appear to be closely related in the nervous system ${ }^{17}$, local alterations in glucose utilization accompany and reflect local changes in neuronal activity in the rat brain ${ }^{11}$. Studies using the $\left[{ }^{14} \mathrm{C}\right] 2$-deoxyglucose histochemistry with intracerebroventricular (i.v.t.) $\beta$-endorphin injection showed the most dramatically enhanced metabolic activity in the ventral hippocampus and the entorhinal cortex, thus favouring these structures as the possible sites of origin for the epileptiform activity ${ }^{9}$.

Using a modification of Sokoloff's technique ${ }^{13}$ and a method for isolated removal of brain tissue ${ }^{15}$, we se- lected some rat brain areas, which from literature and our previous studies appeared to be involved in the neuronal excitability after i.v.t. administration of enkephalins $3,4,7,8$. In the present study, we utilized these methods to ascertain what changes occur in the metabolic rates of different regions in the CNS, during opioid-induced seizures. Therefore, we compared the glucose uptake in some rat brain areas, as a function of time, during a state of normal neural excitability and during $\delta$ receptor peptide ${ }^{5}$ (DSTLE)induced epilepsy. DSTLE as a $\delta$ opiate receptor agonist was selected since the epileptiform phenomena were proposed to emerge from the $\delta$ opiate receptor stimulation 2.8 and probably not from the $\mu$ opiate receptors $^{4,16}$.

\section{MATERIALS AND METHODS}

\section{2-Deoxyglucose uptake}

24 Male Wistar rats (175-200 g) were anesthetized by Hypnorm (fluanison/fentanyl base, Duphar, 0.4

Correspondence: M. R. Dzoljic, Dept. of Pharmacology, Medical Faculty, Erasmus University Rotterdam, P.O. Box 1738, 3000 DR Rotterdam, The Netherlands. 
$\mathrm{ml} / 100 \mathrm{~g}$, s.c.). A steel cannula for i.v.t. injections (coordinates: $\mathrm{AP}-0.1 \mathrm{~mm}$; L $+1.5 \mathrm{~mm}, \mathrm{H} 2.0 \mathrm{~mm}$ from dura, with bregma $0^{6}$ ) was implanted stereotaxically. Each cannula implantation was checked with a positive passage of artificial cerebrospinal fluid (CSF) into the ventricle. All rats were allowed at least a 7-day recovery period. Intraventricular injections were made by a 5- $\mu$ l Hamilton syringe. The 2DG experiments were performed according to the method of Meibach et al. ${ }^{13}$.

The experimental paradigm consisted of i.v.t. injections of DSTLE $(10 \mu \mathrm{g} / 2 \mu \mathrm{l}), 0,2.5,5$ and $10 \mathrm{~min}$ preceding the intravenous administration of 2-DG $(10 \mu \mathrm{Ci} / 100 \mathrm{~g})$. Control animals received CSF $(2 \mu \mathrm{l}$, i.v.t.) instead of DSTLE. $30 \mathrm{~min}$ after the 2-DG injection, the cannula was withdrawn and the animal decapitated. The skull was opened, the brain carefully removed, frozen in dry-ice and stored at $-70{ }^{\circ} \mathrm{C}$ before sectioning.

The brain was cut in $300 \mu \mathrm{m}$ serial sections in a cryostat, maintained at $-20^{\circ} \mathrm{C}$. Brain nuclei were punched with hollow needles, according to Palkovits ${ }^{15}$. Nine individual brain regions were taken from each rat: frontal cortex (FC), parietal cortex (PC), subiculum, including CA1 (S), dentate gyrus (GD), CA3 hippocampal area, central amygdaloid nucleus (ac), cortical amygdaloid nucleus (aco), lateral septal nucleus (SL) and the $n$. parafascicularis thalami (pf).

Tissue pellets were homogenized in $100 \mu$ l of distilled water. An aliquot of $10 \mu \mathrm{l}$ was taken in duplicate for the measurement of proteins ${ }^{12}$.

Radioactivity was determined of two aliquots of 40 $\mu \mathrm{l}$ from the homogenate by liquid scintillation counting. Results are given in pmol $/ 100 \mu \mathrm{g}$ protein. Statistical evaluation was performed by the Mann-Whitney U-test.

\section{Electroencephalographic recording}

Six male rats (Wistar strain, 175-200 g) were anesthetized by urethane $(1.2 \mathrm{~g} / \mathrm{kg}$, i.p. $)$. A tracheal cannula was inserted. A steel cannula for i.v.t. injections and electrodes into the subiculum $(\mathrm{AP}+3.6 \mathrm{~mm}, \mathrm{~L}$ $+0.4 \mathrm{~mm}, \mathrm{H} 3.1 \mathrm{~mm}$ from dura), lateral septum (AP $+1.1 \mathrm{~mm}, \mathrm{~L}+1.2 \mathrm{~mm}, \mathrm{H} 4.6 \mathrm{~mm}$ from dura) and central amygdala (AP $+0.3 \mathrm{~mm}, \mathrm{~L}+4.1 \mathrm{~mm}, \mathrm{H}$ $7.1 \mathrm{~mm}$ from dura with bregma $0^{6}$ ) were implanted stereotaxically. In addition the electrocorticogram of the frontal and parietal cortices was recorded by means of a polygraph Grass model 7.

The regions were selected on basis of the maximum and minimal metabolic rate changes during DSTLE-induced epilepsy. Rectal temperature was maintained between 36.5 and $37.5^{\circ} \mathrm{C}$ with a warm light. After the experiment, the placement of the electrodes was checked histologically.

\section{Drugs}

2-[1-14C ClDeoxy-D-glucose (2-DG; New England Nuclear). 2-DG, $51.1 \mathrm{mCi} / \mathrm{mmol}$, suspended in ethanol-water $(9: 1)$ was placed in a vial and the ethanol medium slowly evaporated with a gentle stream of gaseous nitrogen. The isotope was diluted in sterile $0.9 \%$ saline $(250 \mu \mathrm{Ci} / 2.5 \mathrm{ml})$. The solution was injected intravenously. $\delta$ Receptor peptide (D-TyrSer-Gly-Phe-Leu-Thr, DSTLE, Peninsula Lab.) was dissolved in CSF $(10 \mu \mathrm{g} / 2 \mu \mathrm{l})$ and administered intraventricularly.

\section{RESULTS}

\section{2-DG uptake}

Simultaneous injection of DSTLE $(10 \mu \mathrm{1} / 2 \mu \mathrm{g}$, i.v.t. ) and 2-DG $(10 \mu \mathrm{Ci} / 100 \mathrm{~g}$, i.v. $)$ resulted in an increase of 2-DG uptake in the frontal cortex, subiculum/CA1 area and the cortical amygdala, compared to the controls, which received CSF, $2 \mu$ l (Table I, ' 0 min'). In the other selected brain regions, such as the central amygdala, parietal cortex, lateral septal nucleus, gyrus dentatus, CA3 area and the n. parafascicularis, no differences in the glucose uptake could be observed.

DSTLE administration $2.5 \mathrm{~min}$ prior to the 2-DG pulse resulted in a general increase of the uptake in all regions, most pronounced in the frontal cortex, subiculum/CA1 and the cortical amygdala. Less pronounced uptake of 2-DG occurred in the parietal cortex, dentate gyrus and CA3. No significant increase could be detected in the lateral septal nucleus, central amygdala and the parafascicular nucleus. DSTLE injection, 5 min preceding the 2-DG administration, induced a further significant increase of glucose utilization in the frontal cortex, subiculum and central amygdala. However, a tendency for a decrease in 2-DG uptake can already be observed in all other areas with the exception of CA3. $10 \mathrm{~min}$ after the DSTLE injection, glucose utilization decreased 
TABLE I

Mean values \pm S.E.M. of $2-D G$ uptake

[ $\left.{ }^{14} \mathrm{C}\right] 2$-deoxyglucose $(2-\mathrm{DG}, 10 \mu \mathrm{Ci} / 100 \mathrm{~g}, \mathrm{i} . \mathrm{v}$ ) $)$ uptake in various rat brain areas of control animals (cerebrospinal fluid, CSF, $2 \mu \mathrm{l}$, i.v.t.) and at different time intervals after $\delta$ receptor peptide (DSTLE, $10 \mu \mathrm{g} / 2 \mu \mathrm{l}$, i.v.t.) administration.

\begin{tabular}{|c|c|c|c|c|c|}
\hline \multirow[t]{2}{*}{ Brain area } & \multirow{2}{*}{$\begin{array}{l}\text { CSF } \\
\text { Controls }\end{array}$} & \multicolumn{4}{|c|}{ Time intervals between DSTLE and 2-DG injection } \\
\hline & & $0 \min$ & $2.5 \mathrm{~min}$ & $5 \min$ & $10 \mathrm{~min}$ \\
\hline$\overline{\mathrm{FC}}$ & $22.7 \pm 2.5$ & $30.0 \pm 1.2^{* *}$ & $34.0 \pm 4.6^{* *}$ & $37.4 \pm 2.9^{* *}$ & $25.9 \pm 2.3$ \\
\hline PC & $25.3 \pm 4.6$ & $24.1 \pm 3.6$ & $32.2 \pm 3.8^{*}$ & $24.5 \pm 2.8$ & $24.9 \pm 2.9$ \\
\hline $\mathbf{S}$ & $17.0 \pm 1.7$ & $22.5 \pm 1.5^{*}$ & $29.6 \pm 2.1^{* *}$ & $46.8 \pm 2.2^{* *}$ & $26.1 \pm 1.6^{* *}$ \\
\hline GD & $17.3 \pm 0.9$ & $16.7 \pm 1.3$ & $24.5 \pm 2.2^{*}$ & $20.3 \pm 2.8$ & $19.9 \pm 0.3$ \\
\hline $\mathrm{CA} 3$ & $18.4 \pm 3.9$ & $20.4 \pm 2.0$ & $25.5 \pm 3.0^{*}$ & $26.9 \pm 6.7$ & $20.7 \pm 0.7$ \\
\hline ac & $16.6 \pm 2.6$ & $16.2 \pm 1.5$ & $20.3 \pm 1.4$ & $30.8 \pm 2.6^{* *}$ & $14.2 \pm 1.6$ \\
\hline aco & $23.7 \pm 4.6$ & $31.4 \pm 1.1^{* *}$ & $31.7 \pm 4.3^{* *}$ & $29.2 \pm 3.2$ & $20.1 \pm 1.8$ \\
\hline $\mathrm{SL}$ & $18.6 \pm 2.7$ & $16.6 \pm 1.7$ & $22.1 \pm 2.9$ & $14.9 \pm 9.6$ & $15.9 \pm 3.5$ \\
\hline $\mathrm{pf}$ & $20.5 \pm 1.8$ & $21.8 \pm 0.8$ & $26.1 \pm 3.9$ & $20.0 \pm 7.9$ & $21.2 \pm 2.9$ \\
\hline
\end{tabular}

Note the significant increase of the 2-DG uptake after DSTLE administration in the frontal cortex (FC), subiculum, including CA1 (S) and central and cortical amygdala (ac; aco). A less pronounced increase of the 2-DG uptake can be observed in the dentate gyrus (GD), CA3 hippocampal region and parietal cortex (PC). The 2-DG uptake in the lateral septal nucleus (SL) and n. parafascicularis thalami (pf) was not significantly changed by DSTLE administration. $10 \mathrm{~min}$ after the DSTLE injection a general decrease of the 2-DG uptake occurs. Significant difference compared to controls: ${ }^{* *} P<0.001$ and ${ }^{*} P<0.05$

to control values in all brain regions with the exception of the subiculum.

In the $\mathrm{n}$. parafascicularis and the lateral septal nucleus, the 2-DG uptake was not significantly affected by DSTLE. Because of this general decrease after 10 min, no further experiments, with longer time intervals between the DSTLE and the 2-DG injection, were carried out.

\section{Electroenecephalographic (EEG) recording}

During the EEG recordings in the frontal and parietal cortices, the subiculum, the central amygdala and the lateral septum, an onset period for the DSTLE-induced epileptic discharges of about $30 \mathrm{~s}$ was observed in the subiculum (Fig. 1). These excitatory phenomena appeared a few seconds later in the central amygdala and frontal/parietal cortex.

In all these regions with exception of the lateral septum, the intensity of the spiking exceeded $400 \mu \mathrm{V}$ within $1 \mathrm{~min}$ after the DSTLE administration. However, the most intensive and long-lasting spiking could be observed in the subiculum and central amygdala.

\section{DISCUSSION}

The EEG responses and the results of the 2-DG uptake in this study, indicate that the frontal cortex,

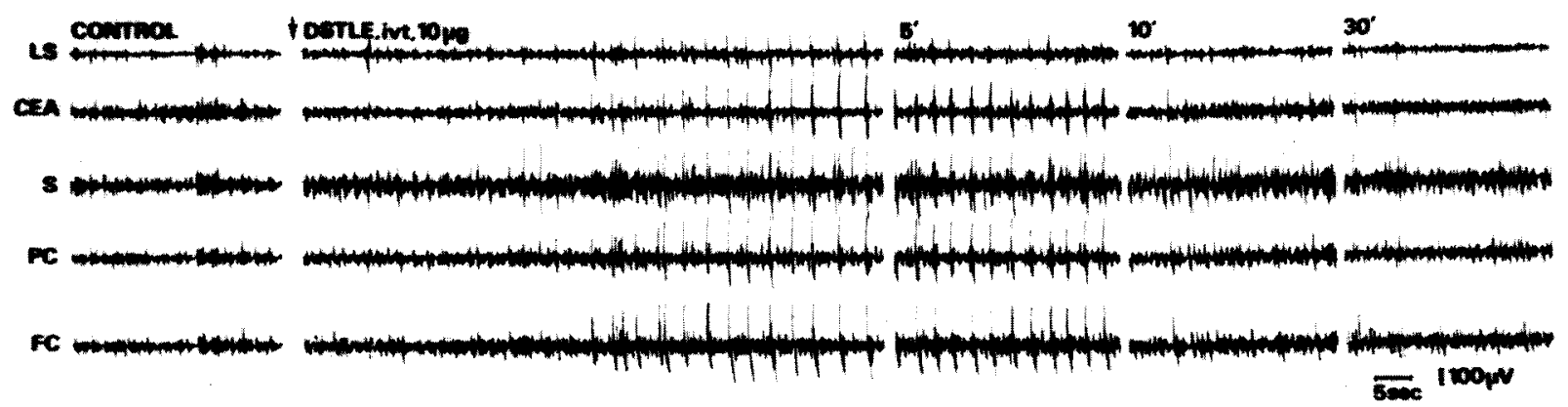

Fig. 1. Electroencephalographic responses of the lateral septum (LS), central amygdala (CEA), subiculum (S), parietal cortex (PC) and frontal cortex (FC), before and after intraventricular (i.v.t.) administration of $\delta$ receptor peptide (DSTLE). Note the unequal spiking activity in the various brain regions at the different time intervals. 
central amygdala and the subiculum/CA1 region, are the main areas involved in the DSTLE-induced epileptic phenomena. These results are generally in accordance with the $\left[{ }^{14} \mathrm{C}\right] 2-\mathrm{DG}$ autoradiographic study of Henriksen et al. ${ }^{9}$, who demonstrated a marked increase of 2-DG uptake in the amygdalohippocampal area after i.v.t. administration of $\beta$-endorphin. Of particular interest is the subiculum, which in this study, includes the pyramidal cell layer of the CA1. In this area the intensity and duration of the increased 2-DG uptake is most pronounced. The electrophysiological responses of this hippocampal region showed the shortest onset of DSTLE-induced epileptiform discharges as well as long-lasting EEG spiking.

Based on electrophysiological studies, it is suggested that opiate evoked epileptiform activity in the limbic system arises from pyramidal cell activity in the hippocampal formation ${ }^{3,20}$. This leads us to suggest that the hippocampus and particularly the subiculum or CA1 area are the probable trigger-zones for seizures induced by an i.v.t. administration of enkephalins. It is not excluded that these regions play an important role in the opiate-modulated neuronal excitability also in physiological and/or pathological conditions in humans. Other hippocampal areas, like $\mathrm{CA} 3$ and the dentate gyrus, showed only a moderate and gradual increase of the 2-DG uptake after DSTLE administration. Although the uptake is significant, it is less intensive compared to the glucose utilization in the subicular region during the epileptic phenomena.

In the lateral septum, we did not find an increase of 2-DG uptake after DSTLE administration, which is in contrast to the data of Henriksen et al. ${ }^{9}$. This controversy might be due to the different activities of $\beta$ endorphin and the enkephalin-analogue, the $\delta$ opiate receptor agonist, DSTLE. However, of particular importance is the fact that in this study the lower level of energy metabolism correlates with the shortlasting and less intensive epileptic discharges in the

\section{REFERENCES}

1 Atweh, S. F. and Kuhar, M. J., Autoradiographic localization of opiate receptors in rat brain. III. The telencephalon, Brain Research, 134 (1977) 393-405.

2 Dzoljic, M. R. and van der Poel-Heisterkamp, A. L., Delta
EEG, compared to the responses of other brain areas. Increase of glucose utilization in the cortical and central nucleus of the amygdala could be due to the fact that the central nucleus is activated following stimulation of different parts of the subiculum. These pathways have been demonstrated by Watson et al. ${ }^{19}$. Furthermore, the central nucleus of the amygdala is rich in enkephalin-containing fiber systems and opiate receptors ${ }^{14}$.

The peak of the 2-DG uptake in the cortical amygdaloid nucleus occurs at about $2.5 \mathrm{~min}$ after DSTLE administration; however, for the central nucleus the peak appears $2.5 \mathrm{~min}$ later. Possibly, the activation pathway runs from the cortical to the central nucleus of the amygdala. The increase of glucose utilization in the frontal cortex after DSTLE administration is probably a reflexion of the excitation of the hippocampal area. Namely, using the 2-DG technique, pronounced labelling of the frontal cortex following elicitation of seizures in the hippocampus has been demonstrated ${ }^{19}$.

Based on these results, we suggest that the hippocampal formation but particularly the subiculum and/or CAl are the probable trigger zones for seizures induced by i.v.t. administration of endorphins. Furthermore, the results indicate a strong relationship between the electrophysiological recordings, the functional activities and glucose utilization/energy metabolism in different rat brain areas, which also supports our earlier observations concerning the brain regions involved in the endorphin-induced epilepsy ${ }^{7,8}$.

\section{ACKNOWLEDGEMENTS}

The authors wish to express their gratitude to F. J. Zijlstra, A. L. van der Poel-Heisterkamp, Y. Bosma and B. H. M. Busscher-Lauw for their technical and secretarial assistance. This work was financially supported by the Dutch Organisation for Health Research TNO, The Hague, CLEO A44.

opiate receptors are involved in the endopioid-induced myoclonic contractions, Brain Res. Bull., 8 (1982) 1-6.

3 French, E. D. and Siggins, G. R., An iontophoretic survey of opioid peptide actions in the rat limbic system: in search of opiate epileptogenic mechanisms, Regulat. Peptides, 1 (1980) 127-146. 
4 Frenk, H., McCarty, B. C. and Liebeskind, J. C., Different brain areas mediate the analgesic and epileptic properties of enkephalin, Science, 200 (1978) 335-337.

5 Gacel, G., Fournie-Zaluski, M.-C. and Roques, B. P., DTyr-Ser-Gly-Phe-Leu-Thr, a highly preferential ligand for $\delta$-opiate receptors, FEBS Lett., 118 (1980) 245-247.

6 König, J. F. R. and Klippel, R. A., The Rat Brain, a Stereotaxic Atlas, Williams and Wilkins, Baltimore, 1963.

7 Haffmans, J., Blankwater, Y. J., Ukponmwan, O. E., Zijlstra, F. J., Vincent, J. E., Hespe, W. and Dzoljic, M. $\mathrm{R}$, Correlation between the distribution of ${ }^{3} \mathrm{H}$-labelled enkephalin in rat brain and the anatomical regions involved in the enkephalin-induced seizures, Neuropharmacology, 22 (1983) 1021-1028.

8 Haffmans, J. and Dzoljic, M. R., Differential epileptogenic potentials of selective $\mu$ and $\delta$ opiate receptor agonists, $J$. Neural Transm., 57 (1983) 1-11.

9 Henriksen, S. J., Chouvet, G., McGinty, J. and Bloom, F. E., Opioid peptides in the hippocampus: anatomical and physiological considerations, Ann. N.Y. Acad. Sci., 398 (1982) 207-220.

10 Illes, P., An unexpected effect of opiates in the limbic system, Trends Pharm. Sci., (1982) 313-314.

11 Kennedy, C., Des Rosiers, M. H., Jehle, J. W., Reivich, M., Sharpe, F. and Sokoloff, L., Mapping of functional neuronal pathways by autoradiographic survey of local metabolic rate with $\left({ }^{14} \mathrm{C}\right)$ deoxyglucose, Science, $187(1975)$ 850-853.

12 Lowry, O. H., Rosebrough, N. J., Farr, A. L. and Randall,
R. J., Protein measurement with the Folin phenol reagent, J. biol. Chem., 193 (1951) 265-275.

13 Meibach, R. C., Glick, S. D., Ross, D. A., Cox, R. D. and Maayani, S., Intraperitoneal administration and other modifications of the 2-deoxy-D-glucose technique, Brain Research, 195 (1980) 167-176.

14 Meibach, R. C. and Maayani, S., Localization of naloxonesensitive $\left({ }^{3} \mathrm{H}\right)$ dihydromorphine binding sites within the hippocampus of the rat, Europ. J. Pharmacol., 68 (1980) 175-179.

15 Palkovits, M., Isolated removal of hypothalamic or other nuclei of the rat, Brain Reserch, 59 (1973) 449-450.

16 Snead, O. C. and Bearden, L. J., Anticonvulsants specific for petit mal antagonize epileptogenic effect of leucine enkephalin, Science, 210 (1980) 1031-1033.

17 Sokoloff, L., Relation between physiological function and energy metabolism in the central nervous system, J. Neurochem., 29 (1977) 13-16.

18 Urca, G., Frenk, H., Liebeskind, J. C. and Taylor, A. N., Morphine and enkephalin: analgesic and epileptic properties, Science, 197 (1977) 83-86.

19 Watson, R. E., Jr., Edinger, H. M. and Siegel, A., A $\left[{ }^{14} \mathrm{C}\right] 2$-deoxyglucose analysis of the functional neural pathways of the limbic forebrain in the rat, III. The hippocampal formation, Brain Res. Rev., 5 (1983) 133-176.

20 Zieglgänsberger, W., French, E. D., Siggins, G. R. and Bloom, F. E., Opioid peptide may excite hippocampal pyramidal neurons by inhibiting adjacent inhibitory interneurons, Science, 205 (1979) 415-417. 